\title{
COMPORTAMENTO FISIOLÓGICO DE SEMENTES DE AÇAÍ (Euterpe oleracea Mart.) SUBMETIDAS À DESIDRATAÇÃ ${ }^{1}$
}

\author{
WALNICE MARIA OLIVEIRA DO NASCIMENTO² \& WALTER RODRIGUES DA SILVA ${ }^{3}$
}

\begin{abstract}
RESUMO - O presente trabalho, objetivando verificar os efeitos imediatos da desidratação sobre o comportamento fisiológico das sementes de açaí (Euterpe oleracea Mart.), utilizou lote oriundo de população de 25 progênies de meio-irmãos, pertencente à Coleção de Germoplasma da Embrapa Amazônia Oriental (Belém/PA). Anteriormente à secagem, foi determinado o grau de umidade das sementes e coletado o tratamento que continha o maior grau de umidade (45\%). As demais sementes foram submetidas à secagem, em câmara com circulação de $\operatorname{ar}\left(30^{\circ} \mathrm{C} \pm 2^{\circ} \mathrm{C}\right)$, visando à obtenção dos demais tratamentos com 39\%, 33\%, 27\%, 22\% e 15\% de água. O efeito da desidratação sobre a qualidade das sementes foi avaliado através das seguintes determinações: grau de umidade, teste de germinação, índice de velocidade de emergência e emergência de plântulas. Foi verificado que a desidratação até 39\% de água não produz efeitos fisiológicos imediatos sobre as sementes de açaí; a partir de 33\% de água, a dessecação favorece progressivamente a redução da germinação e, ao atingir 15\% de água, a capacidade germinativa foi anulada.
\end{abstract}

Termos para indexação: palmácea, fruto, palmito, dessecação.

\section{PHYSIOLOGY BEHAVIOR OF Euterpe oleracea SEEDS SUBMITTED TO DESICCATION}

ABSTRACT - The objective of this article was to verify the physiological effects of desiccation of Euterpe oleracea Mart. seeds. Açai palm seeds from twenty five progenies from the germoplasm collection of Embrapa Amazônia Oriental (Belém, State of Pará, Brazil) were used. Before the desiccation, it was determined the moisture content of the lot and it was removed the treatment with the highest moisture content (45\%). The other seeds of the lot were submitted to drying in a chamber with air circulation at $30 \pm 2^{\circ} \mathrm{C}$ aiming to reach the treatments at $39 \%, 33 \%, 27 \%, 22 \%$ and $15 \%$ of water. The effects of dehydration were evaluated by means of the following determinations: moisture content, germination test, speed and emergency of seedlings. It was concluded that the desiccation to $39 \%$ moisture content does not affect the physiology of Euterpe oleracea seeds, but the drying around $33 \%$ of water reduce the vigour and germination rates. The seeds did not germinate when the moisture content was $15 \%$. Index terms: palmae, fruit, heart of palm, drying.

\section{INTRODUÇÃO}

O açaizeiro (Euterpe oleracea Mart.), palmácea nativa da Amazônia, tem se destacado economicamente pelo potencial mercadológico de seus produtos, representados, principalmente, pelo palmito e pelo suco extraído do fruto.

A média de crescimento do setor produtivo da cultura do açaizeiro tem sido na ordem de $10 \%$ ao ano, devido ao aumento da área plantada, da ampliação da colheita em área de extrativismo e ao aumento na produtividade (Nogueira \& Homma, 1998). A expansão da área cultivada fez crescer a procura por sementes e mudas dessa palmeira. Assim, a exploração extrativista tende a ser parcialmente substituída pela oriunda de campos tecnicamente instalados a partir da disponibilidade de material propagativo (Oliveira et al., 2000).

A estrutura utilizada para a propagação sexuada do açaizeiro, tecnologicamente denominada semente, corresponde ao fruto que, desprovido de epicarpo e de mesocarpo, contém uma semente botânica, com eixo embrionário diminuto e abundante tecido endospermático, de formato esférico e representando $73 \%$ da massa do fruto completo (Villachica et al., 1996; Carvalho et al., 1998). No entanto, os conhecimentos sobre a fisiologia dessa espécie são ainda limitados, sendo essenciais para o desenvolvimento de tecnologias favoráveis à produção e à conservação de suas sementes. A conservação entre a colheita e a semeadura interfere na qualidade e na quantidade das plântulas obtidas e, em decorrência, no desempenho produtivo da população estabelecida no campo.

O grau de umidade determina o comportamento das sementes perante o armazenamento. Em sementes denominadas recalcitrantes, a desidratação causa alterações que favorecem a deterioração (Farrant et al., 1988). De acordo com Carvalho et al. (1998), as sementes de açaizeiro são admitidas como recalcitrantes; dessa maneira, a secagem a graus de umidade próximos a $14 \%$ é suficiente para eliminar a capacidade de germinar (Oliveira et al., 2000).

Diante da escassez de informações sobre o assunto, este trabalho teve o objetivo de verificar os efeitos imediatos da desidratação sobre o comportamento fisiológico das sementes de Euterpe oleracea Mart.

\section{MATERIAL E MÉTODOS}

Foram utilizadas sementes de açaí (Euterpe oleracea Mart.) oriundas de população de 25 progênies de meio-irmãos, pertencente à Coleção de Germoplasma da Embrapa Amazônia Oriental (Belém/PA).

As sementes foram obtidas submetendo frutos maduros recémcolhidos ao despolpamento mecânico, seguido de lavagem do material em água corrente, para a eliminação de resíduos do epicarpo e do mesocarpo. Em seguida, foram realizados a seleção manual e o descarte das sementes malformadas.

Anteriormente à secagem, foi determinado o grau de umidade das sementes do lote e coletado o tratamento que continha o maior grau de umidade (45\%) a ser estudado. As demais sementes foram submetidas à secagem, em equipamento com circulação forçada de $\operatorname{ar}\left(30^{\circ} \mathrm{C} \pm 2^{\circ} \mathrm{C}\right)$, visando à obtenção dos demais tratamentos $(39 \%, 33 \%, 27 \%, 22 \% \mathrm{e}$ $15 \%$ de água) referentes aos graus de umidade desejados. A Figura 1 apresenta a evolução do grau de umidade das sementes durante o processo.

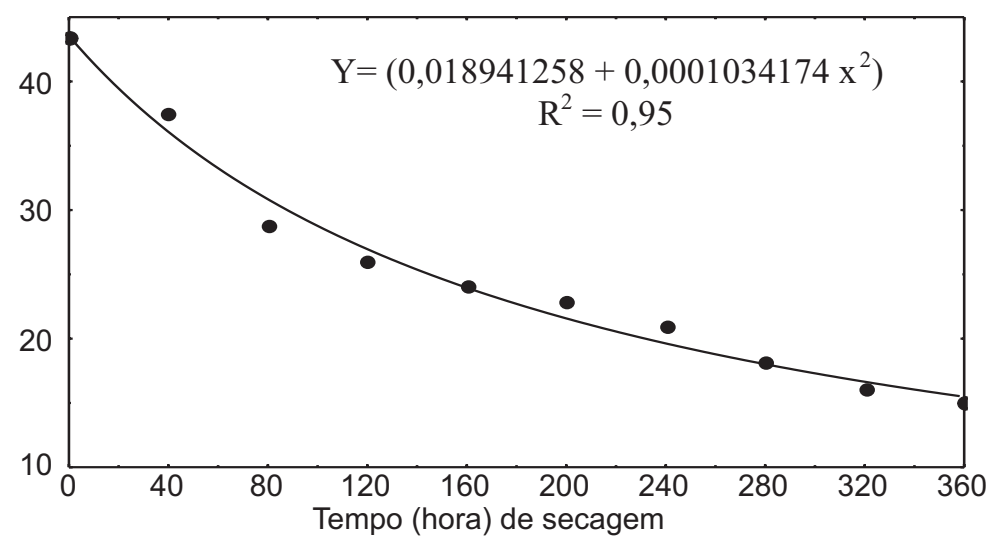

FIGURA 1 - Evolução do grau de umidade, de sementes de Euterpe oleracea, segundo o tempo de secagem a $30^{\circ} \mathrm{C} \pm 2^{\circ} \mathrm{C}$.

\footnotetext{
${ }^{1}$ (Trabalho 001/05). Recebido 05/01/2005. Aceito para publicação: 22/11/2005.

2 Embrapa Amazônia Oriental. Caixa postal 48. CEP 66017-970, Belém-PA - walnice@cpatu.embrapa.br

${ }^{3}$ Departamento de Produção Vegetal, Esalq/USP. Caixa Postal 09. CEP 13418-900, Piracicabal-SP. In memorian
} 
Os tratamentos foram obtidos através do acompanhamento da perda da massa das sementes durante a secagem. Para tanto, amostras de referência, com massas iniciais conhecidas, foram acondicionadas em sacos de filó e distribuídas no secador para pesagem a intervalos regulares. A massa das amostras, correspondentes a cada um dos graus de umidade desejados, foi previamente determinada através da equação descrita por Cromarty et al. (1985).

$\mathrm{Mf}=\mathrm{Mi}(100-\mathrm{Ui}) \times(100-\mathrm{Uf})^{-1}$, onde:

$\mathrm{Mf}=$ massa da amostra $(\mathrm{g})$ após a secagem;

$\mathrm{Mi}=$ massa da amostra $(\mathrm{g})$ antes da secagem;

$\mathrm{Ui}=$ grau de umidade $(\%)$ antes da secagem;

$\mathrm{Uf}=$ grau de umidade $(\%)$ desejado após a secagem.

Foram realizadas as seguintes avaliações da qualidade física e fisiológica das sementes:

Grau de umidade - foi determinado através do método da estufa a $105^{\circ} \mathrm{C} \pm 3^{\circ} \mathrm{C}$, por 24 horas (Brasil, 1992), utilizando 10 sementes por repetição. Os resultados, expressos em porcentagem, foram calculados com base na massa úmida $(\mathrm{Bu})$.

Germinação - foi realizada entre areia umedecida com $70 \%$ de sua capacidade de retenção de água (Brasil, 1992), empregando 25 sementes por repetição instaladas a $1 \mathrm{~cm}$ de profundidade, em ambiente protegido e desprovido de controles de temperatura e de umidade relativa. Os resultados, obtidos aos 90 dias após a semeadura, foram expressos em porcentagem de plântulas normais.

Velocidade de emergência de plântulas - foi obtida utilizando o teste de germinação; para tanto, foram consideradas contagens diárias (90 dias) do número de plântulas expostas acima da superfície do substrato. O cálculo do índice de velocidade de emergência (IVE) considerou a equação proposta por Maguire (1962).

$\operatorname{IVE}=\left(\mathrm{E}_{1} / \mathrm{N}_{1}\right)+\left(\mathrm{E}_{2} / \mathrm{N}_{2}\right)+\ldots+\left(\mathrm{E}_{\mathrm{n}} / \mathrm{N}_{\mathrm{n}}\right)$, onde:

$\mathrm{IVE}=$ Índice de Velocidade de Emergência

$\mathrm{E}_{1}, \mathrm{E}_{2}, \ldots \mathrm{E}_{\mathrm{n}}=$ número de plântulas emersas na primeira, na segunda e na última contagens.

$\mathrm{N}_{1}, \mathrm{~N}_{2}, \ldots, \mathrm{N}_{\mathrm{n}}=$ número de dias da semeadura à primeira, à segunda e à última contagens.

Taxa de emergência de plântulas - foi considerado o número de plântulas emersas existente na última contagem do teste de velocidade de emergência de plântulas (Nakagawa, 1994).

O delineamento experimental adotado foi o inteiramente casualizado, com quatro repetições. As médias foram comparadas pelo teste de Tukey ( $5 \%$ de probabilidade).

\section{RESULTADOS E DISCUSSÃO}

Os graus de umidade determinados foram próximos aos desejados e, dessa maneira, indicaram eficiência do método de secagem adotado para a obtenção dos tratamentos.

Os dados apresentados na Tabela 1 , relativos às determinações fisiológicas (germinação, taxa e velocidade de emergência de plântulas), indicaram ausência de efeitos imediatos da desidratação até 39\% de água; a partir de 33\%, a deterioração foi diretamente proporcional à perda de

TABELA 1 - Teor de água (U), germinação (G), taxa (E) e velocidade (IVE) de emergência de plântulas determinados em sementes de Euterpe oleracea Mart. ${ }^{(1)}$

\begin{tabular}{cccc}
\hline $\begin{array}{c}\text { Tratamento } \\
\text { (grau de umidade) }\end{array}$ & $\begin{array}{c}\mathrm{G} \\
(\%)\end{array}$ & $\begin{array}{c}\mathrm{E} \\
(\%)\end{array}$ & IVE \\
\hline $45 \%$ & $89 \mathrm{a}$ & $91 \mathrm{a}$ & $0,030 \mathrm{a}$ \\
$39 \%$ & $87 \mathrm{a}$ & $90 \mathrm{a}$ & $0,029 \mathrm{a}$ \\
$33 \%$ & $74 \mathrm{~b}$ & $77 \mathrm{~b}$ & $0,027 \mathrm{~b}$ \\
$27 \%$ & $48 \mathrm{c}$ & $54 \mathrm{c}$ & $0,024 \mathrm{~b}$ \\
$22 \%$ & $31 \mathrm{~d}$ & $40 \mathrm{~d}$ & $0,020 \mathrm{c}$ \\
$15 \%$ & $00 \mathrm{e}$ & $00 \mathrm{e}$ & $0,000 \mathrm{~d}$ \\
\hline C.V. $(\%)$ & 3,14 & 1,71 & 1,43 \\
\hline
\end{tabular}

(1) Médias seguidas da mesma letra, na coluna, não diferem entre si, pelo teste de Tukey, a $5 \%$ de probabilidade. água. Dessa maneira, os resultados confirmam o comportamento recalcitrante das sementes de Euterpe oleracea Mart. relatado por Martins et al. (1999a), Araújo et al. (1994) e por Carvalho et al. (1998).

Martins et al. (1999b) verificaram o caráter recalcitrante em sementes de Euterpe espiritosantensis (palmito-vermelho) e comprovaram que a desidratação crescente intensificou o processo de deterioração. Os valores de germinação foram reduzidos, e a mortalidade das sementes foi observada, com a redução do teor de água a $16 \%$.

Adicionalmente, da mesma forma verificada por Oliveira et al. (2000), o desempenho fisiológico das sementes foi imediatamente anulado quando a desidratação atingiu o teor de água de $14 \%$.

Os resultados obtidos assemelham-se aos observados em Euterpe edulis (Martins et al., 2000) e em Bactris gasipaes (Bovi et al., 2004) que, apesar de se tratarem de outras espécies, são palmáceas pertencentes a hábitat semelhante ao de Euterpe oleracea Mart.

\section{CONCLUSÕES}

A desidratação até 39\% de água não produz efeitos imediatos sobre o comportamento fisiológico das sementes de açaí. A partir de $33 \%$, a dessecação favorece progressivamente a redução da germinação e, ao atingir $15 \%$ de água, as sementes não germinam.

\section{AGRADECIMENTOS}

À Embrapa Amazônia Oriental e à equipe coordenada pelo pesquisador João Tomé Farias, pela doação e pela coleta das sementes.

\section{REFERÊNCIAS}

ARAÚJO, E.F; SILVA, R.F.; ARAÚJO, R.F. Avaliação da qualidade de sementes de açaí armazenadas em diferentes embalagens e ambientes. Revista Brasileira de Sementes, Brasília, v.16, n.1, p.7679, 1994.

BOVI, M.L.A.; MARTINS, C.C.; SPIERING, S.H. Desidratação de quatro lotes de pupunheira: efeitos sobre a germinação e o vigor. Horticultura Brasileira, Brasília, v.22, n.1, p.109-112, 2004.

BRASIL. Ministério da Agricultura e Reforma Agrária. Regras para análise de sementes. Brasília: CLAV/DNDV/MA, 1992.365p.

CARVALHO, J.E.U.; NASCIMENTO, W.M.O.; MÜLLER, C.H. Características físicas e de germinação de sementes de espécies frutíferas nativas da Amazônia. Belém: EMBRAPA-CPATU, 1998. 18p. (Boletim de Pesquisa, 203).

CROMARTY,A.S.; ELLIS, R.H.; ROBERTS, E.H. Design of seed storage facilities for genetic conservation. Rome: IPGRI, 1985. 100p.

FARRANT, J.M.; PAMMENTER, N.W.; BERJAK, P. Recalcitrance - a current assessment. Seed Science and Technology, Zurich, v.16, n.1, p.155-166, 1988.

MAGUIRE, J.D. Speed of germination: aid in selection and evaluation for seedling emergence and vigour. Crop Science, Madison, v.2, n.2, p.176-177, 1962.

MARTINS, C.C.; NAKAGAWA, J.; BOVI, M.L.A.; STANGUERLIM, H. Teores crítico e letal de água para sementes de açaizeiro (Euterpe oleracea Mart.). Revista Brasileira de Sementes, Campinas, v.21, n.1, p.125-132, 1999a.

MARTINS, C.C.; NAKAGAWA, J.; BOVI, M.L.A. Tolerância à dessecação de sementes de palmito-vermelho (Euterpe espiritosantensis Fernandes). Revista Brasileira de Botânica, São Paulo, v.22, n.3, p.125-132, 1999b.

MARTINS, C.C.; NAKAGAWA, J.; BOVI, M.L.A. Desiccation tolerance of four seedlots from Euterpe edulis Mart. Seed Science and Technology, Zürich, v.28, n,1, p.101-113, 2000.

NAKAGAWA, J. Testes de vigor baseados na avaliação das plântulas. In: VIEIRA, R.D; CARVALHO, N.M. Testes de vigor em sementes. Jaboticabal: FUNEP, 1994. p.49-85. 
NOGUEIRA, O.L.; HOMMA, A.K.O. Análise econômica de sistemas de manejo de açaizais nativos no estuário amazônico. Belém: EMBRAPA-CPATU, 1998.38p. (Documento, 128).

OLIVEIRA, M S. P.; CARVALHO, J.E.U.; NASCIMENTO, W.M.O. Açaí (Euterpe Oleracea Mart.). Jaboticabal: FUNEP, 2000, 52p. (Série frutas nativas, 7).
VILLACHICA, H.; CARVALHO, J.E.U.; MÜLLER, C.H.; DIAZ S.C.; ALMANZA, M. Frutales y hortalizas promissorios de la Amazonia. Lima: Tratado de Cooperacion Amazonica. Secretaria Pro-tempore, 1996.367p. (TCT-SPT, 44). 